\title{
Precision medicine in the treatment stratification of AML patients: challenges and progress
}

\author{
Ines Lohse ${ }^{1,2,3}$, Kurt Statz-Geary ${ }^{2}$, Shaun P. Brothers ${ }^{1,2,3}$ and Claes Wahlestedt ${ }^{1,2}$ \\ ${ }^{1}$ Center for Therapeutic Innovation, Miller School of Medicine, University of Miami, Miami, FL, USA \\ ${ }^{2}$ Department of Psychiatry and Behavioral Sciences, Miller School of Medicine, University of Miami, Miami, FL, USA \\ ${ }^{3}$ Molecular Therapeutics Shared Resource, Sylvester Comprehensive Cancer Center, University of Miami, FL, USA \\ Correspondence to: Ines Lohse, email: ix1180@med.miami.edu \\ Claes Wahlestedt, email: cwahlestedt@med.miami.edu \\ Keywords: AML; ex vivo drug sensitivity screens; omics-based screens; phenotypic screens; precision medicine \\ Received: September 25, 2018 Accepted: December 10, $2018 \quad$ Published: December 28, 2018
}

Copyright: Lohse et al. This is an open-access article distributed under the terms of the Creative Commons Attribution License 3.0 (CC BY 3.0), which permits unrestricted use, distribution, and reproduction in any medium, provided the original author and source are credited.

\section{ABSTRACT}

Recent advances in high throughput technologies have led to the generation of vast amounts of clinical data and the development of personalized medicine approaches in acute myeloid leukemia (AML). The ability to treat cancer patients based upon their individual molecular characteristics or drug sensitivity profiles is expected to significantly advance cancer treatment and improve the long-term survival of patients with refractory AML, for whom current treatment options are restricted to palliative approaches. The clinical development of omics-based and phenotypic screens, however, is limited by a number of bottlenecks including the generation of cost-effective high-throughput data, data interpretation and integration of multiple approaches, sample availability, clinically relevant timelines, and the development and education of multidisciplinary teams.

Recently, a number of small clinical trials have shown survival benefits in patients treated based on personalized medicine approaches. While these preliminary studies are encouraging, larger trials are needed to evaluate the utility of these technologies in routine clinical settings.

\section{INTRODUCTION}

Increasing incidence rates $(3.4 \%$ per year over the last 10 years) of acute myeloid leukemia (AML) are a growing concern in an aging population [1,2]. Disease heterogeneity resulting from variability in leukemic cell maturation state, a large number of genetic aberrations among patients and existence of multiple disease clones within a single patient present a major challenge in AML treatment. While extensive research efforts over the last decade have shed some light on the biology of AML, overall 5-year survival of AML patients has remained low at $\sim 26 \%[1,2]$ ) and is specifically low in the population of patients that are above 60 years of age (5-15\%) [1, 2]. Significant advances in next generation sequencing technologies have improved understanding of the molecular events that lead to the initiation and propagation of AML. However, until recently, personalized medicine in AML has been limited to characterizing patients into prognosis groups based on karyotypes to guide treatment options. Recent studies suggest that a single AML sample contains around 400 mutations, with 13 of these residing in coding regions $[3,4]$. Several potential driver mutations have been described and include NPM1, CEBPA, DNMT3A, TET2, RUNX1, ASXL1, IDH2, and MLL [5]). This molecular information led to the development of more accurate classification systems and provided new targets for minimal residual leukemia monitoring, and drug discovery and development [6]. In large part because of the increasingly apparent heterogeneity of this disease, too few personalized approaches for patients with AML have been established for clinical use. Modern AML therapy remains based on core principles, which include patient selection for induction chemotherapy, timing of stem cell transplantation and optimal supportive care. Therefore, patients often receive the same standard of care treatments: the nucleoside analogue cytarabine along with a topoisomerase II inhibitor such as daunorubicin, a regimen that is associated with 
significant side effects. In particular, the aggressive nature of the standard of care treatments present major tolerability concerns in older AML patients, a patient population that generally shows rapid disease progression in combination with poor overall health and low tolerance of systemic anti-cancer treatments [2]. Hence, no satisfactory standard treatment exists for this population and most of the patients are physically unable to tolerate aggressive chemotherapy [2]. Therefore emerging approaches in personalized medicine may be key to improving patient outcomes but have been difficult to establish for clinical use due to high costs and long turnover times.

\section{Omics profiling}

The most common form of personalized medicine approaches in the context of AML is the use of genomic molecular profiling in order to define molecular subtypes then select the most appropriate therapy. The development of molecular profiling approaches for AML patients such as whole genome sequencing (WGS), whole exome sequencing (WES), and transcriptome sequencing (RNAseq) have generated certain insight into the biology of AML development, progression and treatment resistance. Indeed, new knowledge concerning the heterogeneous and combinatorial driver events of AML is now being translated into clinics in order to improve treatment planning, drug delivery and exploitation of novel cellular targets.

One of the most successful examples of genetic screening in AML is the treatment of acute promyelocytic leukemia (APL). APL is characterized by the $\mathrm{t}(15 ; 17)$ cytogenetic abnormality, resulting in PML-RARA fusion gene and the negative inhibition of wild type retinoic acid receptor and myeloid differentiation [7]. Treatment of APL using all-trans-retinoic acid (ATRA) and arsenic trioxide (ATO) have resulted in an increase of cure rates from $30 \%$ to $90 \%$ [8]. Other examples of successful advances in individualized AML therapies are core binding factor (CBF) AML and FLT3 mutated AML where patient stratification has significantly increased survival in the patient populations [9].

While the advances in molecular profiling have significantly increased the survival of patients by providing a more advanced classification of AML subtypes for treatment stratification, these technologies have made little impact on patients not falling into such specific subtypes. Several studies are currently evaluating the utility of genomics-guided treatment approaches for AML patients that failed standard-of-care or those were aggressive chemotherapy that is commonly used in AML is not possible (Table 1).

The majority of AML patients have recurrent mutations or chromosomal rearrangements that can be utilized as predictors of clinical outcome and treatment sensitivity [10-17]. A number of patients, however, present with normal karyotype and/or no targetable mutations. In contrast to the genetic alterations, epigenetic changes resulting in aberrant gene expression are reversible and can be targeted pharmacologically. A number of studies have shown that genes regulating DNA methylation are frequently mutated in AML [18] and that epigenetic alterations contribute to the aggressive phenotype of AML [19-28]. Clinically, epigenetic treatment approaches using decitabine and azacitidine have shown encouraging response rates [29-33] and a number of other compounds and protocols are currently being evaluated in Phase I and II clinical trials (Table 1). As yet, prognostic and predictive molecular biomarkers that enable selection of patients who are likely to benefit from epigenetic therapy are not available for clinical testing. While techniques, such as pyrosequencing, for the DNA methylation analyses exist $[32,33]$, they are not currently used for patient stratification.

While the current practice of using WGS or WES for the genetic screening of cancers can provide information about the mutational landscape of individual patients, for most patients the screens cannot inform an effective treatment plan because the majority of observed mutations remain non-targetable. Using only genomics-based screening for the molecular profiling of AML patients fails to recognize changes in transcript splicing and the epigenome. Additionally, these screens fail to evaluate changes in signaling pathways or the metabolome, both of which can significantly impact drug sensitivity independent of mutational status. A recent study interrogated 227 phosphoproteins in $650+$ cancer cell lines and demonstrated that these data were better at predicting drug response than whole genomic or transcriptomic data [34]. Integrating multiple omics approaches in the development of treatment plans, however, can significantly delay patient treatment due to long turnover times and requires the integration of large datasets which can be difficult in a routine clinical setting. Although omics testing has become much more affordable in the last decade, the use of multiple omics tests and complex data analyses significant increase treatment costs. Also, the heterogeneity of AML presents a significant hurdle that needs to be overcome before genetic testing could guide treatment in all cases.

\section{Drug sensitivity testing}

Rather than attempting to match molecular abnormalities to targeted therapies, drug sensitivity testing (DST) approaches, such as ex vivo drug sensitivity screening, use samples of individual patient tumors to evaluate patient-specific drug sensitivity profiles. These assays are especially attractive in AML patients where tumor samples are easily available through peripheral blood draws or bone marrow biopsies and can be evaluated at multiple time points throughout treatment. 
Table 1: Clinical trials evaluating precision medicine approaches in AML patients

\begin{tabular}{|c|c|c|c|}
\hline Study name & Status & Center & Study type \\
\hline $\begin{array}{c}\text { High Throughput Drug Sensitivity Assay and Genomics- } \\
\text { Guided Treatment of Patients With Relapsed or Refractory } \\
\text { Acute Leukemia }\end{array}$ & recruiting & Single center & interventional \\
\hline iCare for Cancer Patients & recruiting & Single center & interventional \\
\hline $\begin{array}{c}\text { Biomarkers in Samples From Adult Patients With Acute } \\
\text { Myeloid Leukemia Who Failed Existing Standard-of-Care } \\
\text { Treatment }\end{array}$ & unknown & unknown & observational \\
\hline $\begin{array}{l}\text { Molecular Characterization of Acute Erythroid Leukemia } \\
\text { (M6-AML) Using Targeted Next-generation Sequencing }\end{array}$ & completed & Single center & observational \\
\hline $\begin{array}{c}\text { Prospective Study of Molecular Predictors of Survival in } \\
\text { Myelodysplastic Syndromes }\end{array}$ & Not recruiting & Single center & interventional \\
\hline $\begin{array}{c}\text { Biomarker Study of Chemotherapy Resistance and Outcomes } \\
\text { in Samples From Older Patients With Acute Myeloid } \\
\text { Leukemia }\end{array}$ & completed & unknown & observational \\
\hline $\begin{array}{c}\text { Accuracy Testing of the Chromosomal Aberration and Gene } \\
\text { Mutation Markers of the AMLProfiler }\end{array}$ & terminated & Multicenter & observational \\
\hline $\begin{array}{c}\text { Genomics-Based Target Therapy for Children With Relapsed } \\
\text { or Refractory Malignancy }\end{array}$ & recruiting & Single center & interventional \\
\hline Beat AML Core Study & recruiting & Single center & interventional \\
\hline $\begin{array}{c}\text { Diagnostic Platform to Perform Centralized and } \\
\text { Standardized Rapid Molecular Diagnosis by Next } \\
\text { Generation Sequencing (NGS) in Patients Diagnosed } \\
\text { WithAcute Myeloid Leukemia. }\end{array}$ & recruiting & Multicenter & observational \\
\hline $\begin{array}{l}\text { ChEmo-Genomics Based Treatment of Acute Myeloid } \\
\text { Leukemia }\end{array}$ & recruiting & Single center & interventional \\
\hline $\begin{array}{c}\text { Treatment for Relapsed/Refractory AML Based on a High } \\
\text { ThroughputDrug Sensitivity Assay }\end{array}$ & Not recruiting & Single center & interventional \\
\hline $\begin{array}{c}\text { Personalized Kinase Inhibitor Therapy Combined } \\
\text { With Chemotherapy in Treating Patients With Newly } \\
\text { Diagnosed Acute Myeloid Leukemia }\end{array}$ & recruiting & Single center & interventional \\
\hline $\begin{array}{l}\text { Next Generation Sequencing (NGS) in Familial Acute } \\
\text { Myeloid Leukemiaand Myelodisplastic Syndromes }\end{array}$ & recruiting & Single center & observational \\
\hline Epigenetic Reprogramming in Relapse/Refractory AML & recruiting & Multicenter & interventional \\
\hline $\begin{array}{c}\text { Biomarker Study of Chemotherapy Resistance and Outcomes } \\
\text { in Samples From Older Patients With Acute Myeloid } \\
\text { Leukemia }\end{array}$ & completed & Single center & unknown \\
\hline $\begin{array}{l}\text { Phase I Epigenetic Priming Using Decitabine With Induction } \\
\text { Chemotherapy in AML }\end{array}$ & completed & Single center & unknown \\
\hline $\begin{array}{c}\text { A Trial of Epigenetic Priming in Patients With Newly } \\
\text { Diagnosed Acute Myeloid Leukemia }\end{array}$ & recruiting & Single center & interventional \\
\hline $\begin{array}{c}\text { Decitabine, Cytarabine, and Daunorubicin Hydrochloride in } \\
\text { Treating Patients with Acute Myeloid Leukemia }\end{array}$ & $\begin{array}{l}\text { Active, Not } \\
\text { Recruiting }\end{array}$ & Multicenter & interventional \\
\hline $\begin{array}{c}\text { Epigenetics, Vitamin C and Abnormal Hematopoiesis - } \\
\text { Pilot Study }\end{array}$ & Recruiting & Single center & interventional \\
\hline $\begin{array}{c}\text { Study of Sensitization of Non-M3 AML Blasts to ATRA by } \\
\text { Epigentic Treatment With Tranylcypromine (TCP) }\end{array}$ & Recruiting & Multicenter & interventional \\
\hline $\begin{array}{l}\text { Decitabine Followed by Idarubicin and Cytarabine in Treating } \\
\text { Patients with Relapsed or Refractory AML and MDS }\end{array}$ & Terminated & Single center & interventional \\
\hline
\end{tabular}


Drug sensitivity testing is a powerful tool for the treatment stratification of AML patients that has been implemented successfully by different groups [34-39]. By relying on drug sensitivity rather than genetic abnormalities, these screens can provide treatment options in the absence of targetable mutations. Generally, drug sensitivity screen utilize libraries of FDA approved compounds. Treating physicians have therefore access to treatment protocols that have been established for AML or can be adapted based on information obtained in other cancers and negotiations with insurance companies can be based on prior use of these drugs.

In contrast to most omics profiling techniques, phenotypic screens can be performed and evaluated in a relatively short time frame and thus allowing physicians to utilize a precision medicine approach without delaying patient treatment. We have shown that drug sensitivity screens can be performed in a clinical setting with a turnaround time of 10 days [35]. Additionally, retesting of liquid biopsies over the course of treatment cycles may allow the physician to rapidly adapt treatment plans in response to developing or changing drug resistance patterns. This will likely also provide insight into how treatment with specific drugs or classes of drugs such as kinase inhibitors influence resistance to non-related compounds like DNA-damaging agents.

A number of recent studies in AML patients reported survival benefits in response to DST-guided therapy. Staib et al. showed that drug sensitivity screening for daunorubicin and cytarabine in AML patients, had a 94\% and $81 \%$ predictive accuracy on the treatment outcome of 57 patients [38]. In this study, other drugs displayed lower predictive accuracy: mitoxantrone 53\%, idarubicin $66 \%$, fludarabine $50 \%$ and thioguanine $22 \%$ [38]. In order to avoid the rapid development of treatment resistances in response to single compound treatment, Kurtz et al. focused on testing combination therapies ex vivo [37]. They found that combining a proliferation inhibitor such as the CDK4/CDK6 inhibitor palbociclib, with an anti-apoptotic agent like the BCL-2 inhibitor venetolax improves treatment efficacy. While these studies displayed high prediction accuracy and increase treatment efficacy, they used only a limited number of compounds, most of which are already routinely used in AML treatment. They also did not consider non-cytotoxic treatment options.

A pilot study recently performed by our group investigated the utility of DST in patients with refractory AML using a compound library of 215 FDA-approved compounds that included cytotoxic drugs commonly used in the treatment of AML and solid tumors as well as a number of non-cytotoxic compounds [35]. The clinical outcome of DST-guided therapy was compared to physician-directed therapy in 12 AML patients. DSTguided therapy resulted in significant increase in treatment responses when compared to patients receiving physicianguided therapies [35]. This study further emphasized the diversity of AML patients with respect to the response towards a larger panel of anti-cancer agents, where no single compound or class of compounds was effective in all of the tested patients. Additionally, the DST assay generally suggested compounds that were not typically considered by the treating physician, such as gemcitabine. Similar results were observed in a study performed by Pemovska et al. in a cohort of chemorefratory AML patients [36]. There, a patient treated based on DST-guided therapy displayed a significant reduction of bone marrow blasts in response to treatment. Both studies [36, 40] used a version of the drug sensitivity scoring, originally developed by Yadav et al. [34], to assess overall drug responses incorporating information on drug potency, efficacy, effect range and therapeutic index, making it possible to rank compounds over multiple clinically relevant parameters. This computational analysis is aimed at creating an unbiased evaluation of treatment responses and generation of clinically relevant treatment suggestions.

While initial studies using DST appear promising, larger trials are necessary to establish clinical diagnostic utility and treatment efficacy. These studies are hampered by the large cohort sizes necessary to adequately evaluate the utility of such large screening libraries and the development of high throughput screening assays that are able to process samples for a large number of patients in a clinically feasible timeframe. A number of trials are currently investigating drug sensitivity testing in the clinical setting (Table 1).

\section{CONCLUSIONS}

AML treatment largely relies on the use of aggressive chemotherapy aimed to induce cancer remission rather than cure. While this treatment approach is moderately successful in some patients, relapse is frequent and most patients, especially those over 60 years of age, rapidly succumb to the disease $[1,2,41]$.

Recent advances in omics technologies have provided unpreceded insight into the biology of AML and also provided numerous novel targets for drug development efforts. A number of studies have demonstrated the extent of genetic variability of AML patients [3-5, 39-41] further emphasizing that the standard one size fits all approach can no longer be justified in this disease.

While genetic screening has led to improved clinical outcomes for certain patients, specifically those with APL and $\mathrm{CBF}$ AML, the majority of genetic aberrations in AML patients are not targetable with currently available drugs [5, 7, 9-12, 41-43]. Even though WGS or WES are used in a number of clinical trial in AML patients, these methods are rarely used to stratify patients due to long turn over times that delay the treatment start [42-44].

Drug sensitivity testing on the other hand, can be performed without delaying patient treatment due 
to short assay times and streamlined analysis. Because most screening libraries contain mainly FDA-approved compounds, treatment implementation is simple for the treating physician and can be done in a routine clinical setting. Although a recent set of small studies have shown significant benefits of stratifying patients based on DST results [34-38], better powered studies will be necessary to further develop the platforms for routine clinical use.

In the ASCO (American Society of Oncology) guideline published by Samson et al. (2005) [45], prospective studies comparing assay directed treatment and empiric treatment were critically reviewed and the authors concluded that no benefit was obvious for the former approach. These guidelines were updated in 2011 and the conclusion remained the same [46]. Previous efforts to predict responsiveness to therapy in cancer patients based on a priori laboratory testing, have been limited to the use of conventional chemotherapy drugs for patients with solid tumors [36, 47-57] and hampered by long turn around times that delayed patient treatment. In addition, the ex-vivo responses were often non-selective, difficult to interpret, and challenging to translate into clinical practice. Indeed, for most approaches, clinical validation of candidate agents was lacking [47, 48, 50, 53-57]. In many cases, treatment proposed by an assay did not differ from what the clinician would have selected empirically. In the time since the last ASCO review in 2011, significant progress has been made in both the assay technology as well as the analysis of drug sensitivity screening approaches and the majority of the limitations have been addressed. Specifically, the ability to analyze larger compound libraries allows for treatment proposals outside the clinical routine. The development of novel analysis algorithms addressing previous difficulties in cancer selectivity and assay interpretation [34-36]. Cancer selectivity in particular has been addressed by Swords et al. [35] through the use of normal white blood cells as a surrogate for normal tissue toxicity allowing for the selection of agents with high cancer and low normal toxicity thus reducing treatment side effects. The use of these drug sensitivity screens in larger randomized clinical trial will demonstrate feasibility of these approaches in a clinical routine setting.

Both, omics and DST, approaches generate significantly different datasets that are valuable for understanding the biology of AML and stratifying patients for treatment. While DST approaches seems to be clinically more advanced for treatment stratification, patients would benefit from precision medicine approaches combining multiple omics strategies, such as WGS/WES and epigenetic screening, with drug sensitivity testing. A recent study describing the initial findings from the Beat AML program has aimed to integrate wholegenome sequencing, RNA sequencing and drug sensitivity testing in a large cohort of AML patients [58]. This study generated a large dataset using 672 tumor specimens from 562 patients. The integration of mutational status, gene expression and response to a panel of 122 small molecules allows the comparison of specific mutations and drug response, thus providing a powerful tool for drug development [58]. However, the data was not used to stratify patients for treatment and did not address the clinical utility of either of the evaluated methods [58]. By combining these unique datasets for patient stratification in a clinical setting, we may improve the survival rates for today's AML patients and gain further insight into the molecular and genetic diversity of this complex disease.

\section{CONFLICTS OF INTEREST}

The authors have no conflict of interest to declare.

\section{FUNDING}

SB received support from the National Institutes of Health (R01NS092671 and R01MH110441). CW's laboratory is currently publically funded by NIH grants DA035592, DA035055 and AA023781, and Florida Department of Health grants 6AZ08 and 7AZ26.

\section{REFERENCES}

1. Cancer Facts \& Figures. 2017. https://www.cancer.org/ content/dam/cancer-org/research/cancer-facts-and-statistics/ annual-cancer-facts-and-figures/2017/cancer-facts-andfigures-2017.pdf.

2. Institute NC. Surveillance, Epidemiology, and End Results (SEER) Program 2007-2013.

3. Ley TJ, Miller C, Ding L, Raphael BJ, Mungall AJ, Robertson A, Hoadley K, Triche TJ Jr, Laird PW, Baty JD, Fulton LL, Fulton R, Heath SE, et al, and Cancer Genome Atlas Research Network. Genomic and epigenomic landscapes of adult de novo acute myeloid leukemia. N Engl J Med. 2013; 368:2059-74. https://doi.org/10.1056/NEJMoa1301689.

4. Welch JS, Ley TJ, Link DC, Miller CA, Larson DE, Koboldt DC, Wartman LD, Lamprecht TL, Liu F, Xia J, Kandoth C, Fulton RS, McLellan MD, et al. The origin and evolution of mutations in acute myeloid leukemia. Cell. 2012; 150:26478. https://doi.org/10.1016/j.cell.2012.06.023.

5. Döhner H, Gaidzik VI. Impact of genetic features on treatment decisions in AML. Hematology (Am Soc Hematol Educ Program). 2011; 2011:36-42. https://doi.org/10.1182/ asheducation-2011.1.36.

6. Smith FO. Personalized medicine for AML? Blood. 2010; 116:2622-3. https://doi.org/10.1182/blood-2010-07-296418.

7. Raelson JV, Nervi C, Rosenauer A, Benedetti L, Monczak Y, Pearson M, Pelicci PG, Miller WH Jr. The PML/RAR alpha oncoprotein is a direct molecular target of retinoic acid in acute promyelocytic leukemia cells. Blood. 1996; 88:2826-32. 
8. Tallman MS, Nabhan C, Feusner JH, Rowe JM. Acute promyelocytic leukemia: evolving therapeutic strategies. Blood. 2002; 99:759-67.

9. Alan K. Burnett RKH, Nigel Russell, Donald Milligan, Ann E. Hunter, Richard E. Clark, David Bowen and Mary Frances McMullin. Reasons for survival improvement in core binding factor AML: a 25 year analysis of the UK MRC/NCRI AML trials. Blood. 2013; 122:358.

10. Mrozek K, Heerema NA, Bloomfield CD. Cytogenetics in acute leukemia. Blood Rev. 2004; 18:115-36. https://doi. org/10.1016/S0268-960X(03)00040-7.

11. Caligiuri MA, Strout MP, Lawrence D, Arthur DC, Baer MR, Yu F, Knuutila S, Mrozek K, Oberkircher AR, Marcucci G, de la Chapelle A, Elonen E, Block AW, et al. Rearrangement of ALL1 (MLL) in acute myeloid leukemia with normal cytogenetics. Cancer Res. 1998; 58:55-9.

12. Gilliland DG, Griffin JD. Role of FLT3 in leukemia. Curr Opin Hematol. 2002; 9:274-81.

13. Dohner K, Schlenk RF, Habdank M, Scholl C, Rucker FG, Corbacioglu A, Bullinger L, Frohling S, Dohner H. Mutant nucleophosmin (NPM1) predicts favorable prognosis in younger adults with acute myeloid leukemia and normal cytogenetics: interaction with other gene mutations. Blood. 2005; 106:3740-6. https://doi.org/10.1182/ blood-2005-05-2164.

14. Baldus CD, Liyanarachchi S, Mrozek K, Auer H, Tanner SM, Guimond M, Ruppert AS, Mohamed N, Davuluri RV, Caligiuri MA, Bloomfield CD, de la Chapelle A. Acute myeloid leukemia with complex karyotypes and abnormal chromosome 21: Amplification discloses overexpression of APP, ETS2, and ERG genes. Proc Natl Acad Sci U S A. 2004; 101:3915-20. https://doi.org/10.1073/pnas.0400272101.

15. Baldus CD, Tanner SM, Ruppert AS, Whitman SP, Archer KJ, Marcucci G, Caligiuri MA, Carroll AJ, Vardiman JW, Powell BL, Allen SL, Moore JO, Larson RA, et al. BAALC expression predicts clinical outcome of de novo acute myeloid leukemia patients with normal cytogenetics: a Cancer and Leukemia Group B Study. Blood. 2003; 102:1613-8. https://doi.org/10.1182/blood-2003-02-0359.

16. Heuser M, Beutel G, Krauter J, Dohner K, von Neuhoff N, Schlegelberger B, Ganser A. High meningioma 1 (MN1) expression as a predictor for poor outcome in acute myeloid leukemia with normal cytogenetics. Blood. 2006; 108:3898905. https://doi.org/10.1182/blood-2006-04-014845.

17. Welch JS, Westervelt P, Ding L, Larson DE, Klco JM, Kulkarni S, Wallis J, Chen K, Payton JE, Fulton RS, Veizer J, Schmidt H, Vickery TL, et al. Use of whole-genome sequencing to diagnose a cryptic fusion oncogene. JAMA. 2011; 305:1577-84. https://doi.org/10.1001/jama.2011.497.

18. Voso MT, Scardocci A, Guidi F, Zini G, Di Mario A, Pagano L, Hohaus S, Leone G. Aberrant methylation of DAP-kinase in therapy-related acute myeloid leukemia and myelodysplastic syndromes. Blood. 2004; 103:698-700. https://doi.org/10.1182/blood-2003-07-2249.
19. Seedhouse CH, Das-Gupta EP, Russell NH. Methylation of the hMLH1 promoter and its association with microsatellite instability in acute myeloid leukemia. Leukemia. 2003; 17:83-8. https://doi.org/10.1038/sj.leu.2402747.

20. Melki JR, Vincent PC, Brown RD, Clark SJ. Hypermethylation of E-cadherin in leukemia. Blood. 2000; 95:3208-13.

21. Issa JP, Zehnbauer BA, Kaufmann SH, Biel MA, Baylin SB. HIC1 hypermethylation is a late event in hematopoietic neoplasms. Cancer Res. 1997; 57:1678-81.

22. Plass C, Yu F, Yu L, Strout MP, El-Rifai W, Elonen E, Knuutila S, Marcucci G, Young DC, Held WA, Bloomfield $\mathrm{CD}$, Caligiuri MA. Restriction landmark genome scanning for aberrant methylation in primary refractory and relapsed acute myeloid leukemia; involvement of the WIT-1 gene. Oncogene. 1999; 18:3159-65. https://doi.org/10.1038/ sj.onc. 1202651.

23. Agrawal S, Hofmann WK, Tidow N, Ehrich M, van den Boom D, Koschmieder S, Berdel WE, Serve H, Muller-Tidow C. The C/EBPdelta tumor suppressor is silenced by hypermethylation in acute myeloid leukemia. Blood. 2007; 109:3895-905. https://doi.org/10.1182/ blood-2006-08-040147.

24. Esteller M. Profiling aberrant DNA methylation in hematologic neoplasms: a view from the tip of the iceberg. Clin Immunol. 2003; 109:80-8.

25. Melki JR, Vincent PC, Clark SJ. Concurrent DNA hypermethylation of multiple genes in acute myeloid leukemia. Cancer Res. 1999; 59:3730-40.

26. Toyota M, Kopecky KJ, Toyota MO, Jair KW, Willman CL, Issa JP. Methylation profiling in acute myeloid leukemia. Blood. 2001; 97:2823-9.

27. Zhan D, Zhang Y, Xiao P, Zheng X, Ruan M, Zhang J, Chen A, Zou Y, Chen Y, Huang G, Hu S, Wang QF, Zhu $\mathrm{X}$. Whole exome sequencing identifies novel mutations of epigenetic regulators in chemorefractory pediatric acute myeloid leukemia. Leuk Res. 2018; 65:20-4. https://doi. org/10.1016/j.leukres.2017.12.001.

28. Abaza YM, Kadia TM, Jabbour EJ, Konopleva MY, Borthakur G, Ferrajoli A, Estrov Z, Wierda WG, Alfonso A, Chong TH, Chuah C, Koh LP, Goh BC, et al. Phase 1 dose escalation multicenter trial of pracinostat alone and in combination with azacitidine in patients with advanced hematologic malignancies. Cancer. 2017; 123:4851-9. https://doi.org/10.1002/cncr.30949.

29. Halpern AB, Othus M, Huebner EM, Buckley SA, PogosovaAgadjanyan EL, Orlowski KF, Scott BL, Becker PS, Hendrie PC, Chen TL, Percival MM, Estey EH, Stirewalt DL, Walter RB. Mitoxantrone, etoposide and cytarabine following epigenetic priming with decitabine in adults with relapsed/ refractory acute myeloid leukemia or other high-grade myeloid neoplasms: a phase 1/2 study. Leukemia. 2017; 31:2560-7. https://doi.org/10.1038/leu.2017.165.

30. Ragon BK, Daver N, Garcia-Manero G, Ravandi F, Cortes J, Kadia T, Oran B, Ohanian M, Ferrajoli A, Pemmaraju 
N, Kantarjian HM, Borthakur G. Minimal residual disease eradication with epigenetic therapy in core binding factor acute myeloid leukemia. Am J Hematol. 2017; 92:845-50. https://doi.org/10.1002/ajh.24782.

31. Hiller JK, Schmoor C, Gaidzik VI, Schmidt-Salzmann C, Yalcin A, Abdelkarim M, Blagitko-Dorfs N, Dohner K, Bullinger L, Duyster J, Lubbert M, Hackanson B. Evaluating the impact of genetic and epigenetic aberrations on survival and response in acute myeloid leukemia patients receiving epigenetic therapy. Ann Hematol. 2017; 96:559 65. https://doi.org/10.1007/s00277-016-2912-7.

32. Uy GL, Duncavage EJ, Chang GS, Jacoby MA, Miller CA, Shao J, Heath S, Elliott K, Reineck T, Fulton RS, Fronick CC, O'Laughlin M, Ganel L, et al. Dynamic changes in the clonal structure of MDS and AML in response to epigenetic therapy. Leukemia. 2017; 31:872-81. https://doi. org/10.1038/leu.2016.282.

33. Li J, Zhao W, Akbani R, Liu W, Ju Z, Ling S, Vellano CP, Roebuck P, Yu Q, Eterovic AK, Byers LA, Davies MA, Deng W, et al. Characterization of Human Cancer Cell Lines by Reverse-phase Protein Arrays. Cancer Cell. 2017; 31:225-39. https://doi.org/10.1016/j.ccell.2017.01.005.

34. Yadav B, Pemovska T, Szwajda A, Kulesskiy E, Kontro M, Karjalainen R, Majumder MM, Malani D, Murumagi A, Knowles J, Porkka K, Heckman C, Kallioniemi O, et al. Quantitative scoring of differential drug sensitivity for individually optimized anticancer therapies. Sci Rep. 2014; 4:5193.

35. Swords RT, Azzam D, Al-Ali H, Lohse I, Volmar CH, Watts JM, Perez A, Rodriguez A, Vargas F, Elias R, Vega F, Zelent A, Brothers SP, et al. Ex-vivo sensitivity profiling to guide clinical decision making in acute myeloid leukemia: A pilot study. Leuk Res. 2018; 64:34-41. https://doi.org/10.1016/j. leukres.2017.11.008.

36. Pemovska T, Kontro M, Yadav B, Edgren H, Eldfors S, Szwajda A, Almusa H, Bespalov MM, Ellonen P, Elonen E, Gjertsen BT, Karjalainen R, Kulesskiy E, et al. Individualized systems medicine strategy to tailor treatments for patients with chemorefractory acute myeloid leukemia. Cancer Discov. 2013; 3:1416-29. https://doi. org/10.1158/2159-8290.CD-13-0350.

37. Kurtz SE, Eide CA, Kaempf A, Khanna V, Savage SL, Rofelty A, English I, Ho H, Pandya R, Bolosky WJ, Poon $\mathrm{H}$, Deininger MW, Collins R, et al. Molecularly targeted drug combinations demonstrate selective effectiveness for myeloid- and lymphoid-derived hematologic malignancies. Proc Natl Acad Sci U S A. 2017; 114:E7554-E63. https:// doi.org/10.1073/pnas.1703094114.

38. Staib P, Staltmeier E, Neurohr K, Cornely O, Reiser M, Schinkothe T. Prediction of individual response to chemotherapy in patients with acute myeloid leukaemia using the chemosensitivity index Ci. Br J Haematol. 2005; 128:78391. https://doi.org/10.1111/j.1365-2141.2005.05402.x.

39. Aziz H, Ping CY, Alias H, Ab Mutalib NS, Jamal R. Gene Mutations as Emerging Biomarkers and Therapeutic Targets for Relapsed Acute Myeloid Leukemia. Front Pharmacol. 2017; 8:897. https://doi.org/10.3389/fphar.2017.00897.

40. Brade A, MacRae R, Laurie SA, Bezjak A, Burkes R, Chu Q, Goffin JR, Cho J, Hope A, Sun A, Leighl N, Capobianco S, Feld R, et al. Phase II Study of Concurrent Pemetrexed, Cisplatin, and Radiation Therapy for Stage IIIA/B Unresectable Non-Small Cell Lung Cancer. Clin Lung Cancer. 2016; 17:133-41. https://doi.org/10.1016/j.cllc.2015.12.008.

41. Sweet K, Lancet J. State of the Art Update and Next Questions: Acute Myeloid Leukemia. Clin Lymphoma Myeloma Leuk. 2017; 17:703-9. https://doi.org/10.1016/j. clml.2017.10.005.

42. Papaemmanuil E, Gerstung M, Bullinger L, Gaidzik VI, Paschka P, Roberts ND, Potter NE, Heuser M, Thol F, Bolli N, Gundem G, Van Loo P, Martincorena I, et al. Genomic Classification and Prognosis in Acute Myeloid Leukemia. N Engl J Med. 2016; 374:2209-21. https://doi.org/10.1056/ NEJMoa1516192.

43. Patel JP, Gonen M, Figueroa ME, Fernandez H, Sun Z, Racevskis J, Van Vlierberghe P, Dolgalev I, Thomas $\mathrm{S}$, Aminova O, Huberman $\mathrm{K}$, Cheng J, Viale A, et al. Prognostic relevance of integrated genetic profiling in acute myeloid leukemia. N Engl J Med. 2012; 366:1079-89. https://doi.org/10.1056/NEJMoa1112304.

44. Metzeler KH, Herold T, Rothenberg-Thurley M, Amler S, Sauerland MC, Görlich D, Schneider S, Konstandin NP, Dufour A, Bräundl K, Ksienzyk B, Zellmeier E, Hartmann L, et al, and AMLCG Study Group. Spectrum and prognostic relevance of driver gene mutations in acute myeloid leukemia. Blood. 2016; 128:686-98. https://doi.org/10.1182/ blood-2016-01-693879.

45. Samson DJ, Seidenfeld J, Ziegler K, Aronson N. Chemotherapy sensitivity and resistance assays: a systematic review. J Clin Oncol. 2004; 22:3618-30. https:// doi.org/10.1200/JCO.2004.04.077.

46. Schrag D, Garewal HS, Burstein HJ, Samson DJ, Von Hoff DD, Somerfield MR, and ASCO Working Group on Chemotherapy Sensitivity and Resistance Assays. American Society of Clinical Oncology Technology Assessment: chemotherapy sensitivity and resistance assays. J Clin Oncol. 2004; 22:3631-8. https://doi.org/10.1200/JCO.2004.05.065.

47. Bosanquet AG, Bell PB. Ex vivo therapeutic index by drug sensitivity assay using fresh human normal and tumor cells. J Exp Ther Oncol. 2004; 4:145-54.

48. Brigulova K, Cervinka M, Tosner J, Sedlakova I. Chemoresistance testing of human ovarian cancer cells and its in vitro model. Toxicol In Vitro. 2010; 24:2108-15. https://doi.org/10.1016/j.tiv.2010.08.010.

49. Davis MI, Hunt JP, Herrgard S, Ciceri P, Wodicka LM, Pallares G, Hocker M, Treiber DK, Zarrinkar PP. Comprehensive analysis of kinase inhibitor selectivity. Nat Biotechnol. 2011; 29:1046-51. https://doi.org/10.1038/ nbt.1990.

50. Ehemann V, Kern MA, Breinig M, Schnabel PA, Gunawan B, Schulten HJ, Schlaeger C, Radlwimmer B, Steger 
CM, Dienemann H, Lichter P, Schirmacher P, Rieker RJ. Establishment, characterization and drug sensitivity testing in primary cultures of human thymoma and thymic carcinoma. Int J Cancer. 2008; 122:2719-25. https://doi. org/10.1002/ijc.23335.

51. Gustavsson A, Olofsson T. Prediction of response to chemotherapy in acute leukemia by in vitro drug sensitivity testing on leukemic stem cells. Cancer Res. 1984; 44:4648-52.

52. Iwadate Y, Fujimoto S, Namba H, Yamaura A. Promising survival for patients with glioblastoma multiforme treated with individualised chemotherapy based on in vitro drug sensitivity testing. Br J Cancer. 2003; 89:1896-900. https:// doi.org/10.1038/sj.bjc.6601376.

53. Larsson R, Nygren P. Laboratory prediction of clinical chemotherapeutic drug resistance: a working model exemplified by acute leukaemia. Eur J Cancer. 1993; 29A:1208-12.

54. Lehnhardt M, Muehlberger T, Kuhnen C, Brett D, Steinau HU, Jafari HJ, Steinstraesser L, Muller O, Homann HH. Feasibility of chemosensitivity testing in soft tissue sarcomas. World J Surg Oncol. 2005; 3:20. https://doi. org/10.1186/1477-7819-3-20.

55. Pieters R, Loonen AH, Huismans DR, Broekema GJ, Dirven MW, Heyenbrok MW, Hahlen K, Veerman AJ. In vitro drug sensitivity of cells from children with leukemia using the MTT assay with improved culture conditions. Blood. 1990; 76:2327-36.

56. Villman K, Blomqvist C, Larsson R, Nygren P. Predictive value of in vitro assessment of cytotoxic drug activity in advanced breast cancer. Anticancer Drugs. 2005; 16:609-15.

57. Yamada S, Hongo T, Okada S, Watanabe C, Fujii Y, Ohzeki T. Clinical relevance of in vitro chemoresistance in childhood acute myeloid leukemia. Leukemia. 2001; 15:1892-7.

58. Tyner JW, Tognon CE, Bottomly D, Wilmot B, Kurtz SE, Savage SL, Long N, Schultz AR, Traer E, Abel M, Agarwal A, Blucher A, Borate U, et al. Functional genomic landscape of acute myeloid leukaemia. Nature. 2018; 562:526-31. https://doi.org/10.1038/s41586-018-0623-z. 